Article

\title{
Properties of Latex Polymer Modified Mortars Reinforced with Waste Bamboo Fibers from Construction Waste
}

\author{
Banjo Akinyemi ${ }^{1, *}$ (i) and Temidayo Omoniyi ${ }^{2}$ \\ 1 Department of Agricultural and Biosystems Engineering, Landmark University, P.M.B. 1001, \\ 23451 Omu-Aran, Nigeria \\ 2 Department of Wood Products Engineering, University of Ibadan, 23402 Ibadan, Nigeria; \\ temidayoomoniyi@gmail.com \\ * Correspondence: akinyemi.banjo@lmu.edu.ng
}

Received: 25 September 2018; Accepted: 17 October 2018; Published: 5 November 2018

\begin{abstract}
This study evaluated the properties of latex modified cement mortars from ordinary paints which were reinforced with treated bamboo fibers from construction waste. Fiber variations of $0,0.5,1$ and $1.5 \%$ at $10 \%$ of the weight of cement were utilized. Mechanical properties were determined according to standards; similarly, scanning electron microscopy (SEM) and energy dispersive spectroscopy (EDS) were used to analyze the microstructural and elemental properties of the samples. The experimental results revealed that the addition of $1.5 \%$ bamboo fibers and $10 \%$ latex solution produced excellent mechanical properties. This was as a result of improved fiber adhesion to the matrix through pre-treatment, coupled with the contributed high strength from the latex paint modified mortars. The micrograph showed that latex precipitated in the voids and on the surface of the bamboo fibers as well as gels of calcium silicate hydrates which contributed to the observed improvement in strength of the tested samples.
\end{abstract}

Keywords: bamboo; fibers; waste; cement; construction; composites

\section{Introduction}

Some of the potential deficiencies of cement mortar include poor tensile strength, high porosity, crack formation, poor impact strength, water permeability and low chemical resistance [1-3]. Polymer modification has been used as a technique to overcome some of these shortcomings in conventional mortar for close to 80 years now [4]. This is achieved by creating a synergetic interaction between the cement matrix and polymers to improve the physical and mechanical properties of the polymer composite material that is formed. This modification changes the properties of fresh mortar by improving workability and retardation of cement hydration which ultimately gives a good performance to the mortar in its hardened form [5]. It has been observed that there are changes in compressive strength, physical properties and microstructures in polymer modified mortar that is used for construction in tropical climates, where there is abundance of sunlight and rainfall all through the year [6,7]. Therefore, to improve the strength of polymer mortar, the partial replacement of cement with latex polymers and reinforcement with cellulose fibers in regions of high temperature and high relative humidity is proposed. Latex paint consists of pigments, binders, solvents and additives. The binders are the film forming component of the paint as it dries, affecting the durability, gloss, and flexibility of the coating. Such binders include polyurethanes, polyesters, and acrylics which could serve as a replacement for the more expensive polymers used for mortar modification. Latex paint is widely available in most markets in many developing nations in Sub-Saharan Africa. This paint is cheap, and most importantly, it is water based, which typifies that it could be mixed easily with 
water-based cement. In addition to this, it requires no anti-foaming additive, as recommended by Scott and Nathaniel [8]. There is no landfill or dumpsite where waste latex paints could be sourced from in most of these developing countries. This is because every ounce of the paint produced by the industries is used up, while the products are entirely put to use by the consumers of these products, hence the acquisition of waste latex paints is nearly impossible. Polymers in either powder form or dispersion form are not easily accessible to most people in this part of the world. This is because these polymers have to be purchased and shipped to the desired location, thereby making it expensive and beyond the reach of low-income earners that may desire to use them for their high strength value. The major chemical constituents of paints have features very close to polymer admixtures, which are chemical additives used for the enhancement of cement and mortar technologies to produce composite materials with superior strength [9]. Paints consist of multitudes of small particles in the range of $0.1 \mu \mathrm{m}$ to $10 \mu \mathrm{m}$, which falls under the classification of fine and ultra-fine substances. It had been reported that by including large amounts of ultrafine fillers with a small quantity of cement, a high strength mortar would be formed, which would also save cost by limiting the amount of cement used [10]. Various concluded research has shown that properties such as chemical resistance, damping ability and flexibility of latexes are used in improving mortar, and another major value addition by latex to mortar modification is the reduction in water permeability, due to the film formation that covers the voids that remain after cement hydration had taken place [11-15]. Some proponents of sustainable construction have suggested the use of non-conventional agricultural wastes as a construction material because of their relative abundance, environmental friendliness, comparable strength with synthetic fibers and low cost which is in contrast to synthetic fibers which have a high resistance to biodegradation and are costly to procure. These natural fibers had been successfully used in fiber reinforced polymer mortar composites with outstanding results after treatment. Such studies included Jiaxin and Nawawi [16], Libo and Nawawi [17], Ali and Fereidoon [18] and Sumit et al. [19]. Bamboo is an important source of natural fibre which has been in use for construction purposes since centuries past. In many developing countries in Africa, most especially in Nigeria, bamboo is readily available, accessible and mostly used as scaffolding material in small scale construction in urban areas. Bamboo is also useful in furniture production, paper making and textile making [20]. Moreover, based on the cheap cost, it is mostly preferred to steel as a scaffolding material, but at the end of construction it is dumped in a landfill, thereby constituting an environmental challenge because of disposal issues. Tons of bamboo waste can be recovered from construction and demolition dumpsites and reused to develop a sustainable mortar in developing areas with good performance when compared with other synthetic fibers [21]. Two combined treatments were adopted in the study to improve the strength of a conventional mortar, these include cement matrix modification and alkali treatment of the cellulose fiber used.

\section{Experimental Work}

\subsection{Materials}

Discarded bamboo culms used as a scaffold from a completed construction site were selected based on visual inspection. Nails, metal strips of wire and other extraneous materials were removed from the culms and subsequently the bamboo nodes were broken with a hammer. They were pre-cut into strips $400 \mathrm{~mm}$ in length and then cut further into chips of $30 \mathrm{~mm}$ before being hammer milled. Thereafter, bamboo fibers that passed through a $1.18 \mathrm{~mm}$ mesh sieve were used. The acrylic latex paint used had a viscosity at $30^{\circ} \mathrm{C}$ of 10.30 (mPa.S), a density of $2.15 \mathrm{~g} / \mathrm{cm}^{3}$ and a refractive index of 1.4210 . For the mortar, Portland cement Type I for general use was procured; fine sand passing through a $2.0 \mathrm{~mm}$ sieve from river sand was also used.

\subsection{Surface Treatment of Bamboo Fibers}

For treatment of bamboo fibers, they were soaked in water to remove dust, debris and other unwanted objects. They were then immersed in a $10 \%$ weight $\mathrm{NaOH}$ solution that was retrieved after 
dissolving the pellets in distilled water. Soaking of the fibers in solution was done for $24 \mathrm{~h}$ in the laboratory at $30^{\circ} \mathrm{C}$ before the fibers were removed and rinsed three times in $100 \mathrm{~L}$ volume of fresh water. This was done to allow leaching of the alkali from the fibers. Finally, the washed fibers were naturally dried in the laboratory for $120 \mathrm{~h} \mathrm{[22].}$

\subsection{Production of Composite Mortar Samples}

For the development of the high strength mortar composites, the composition of each constituents in the volume of the matrix was $0-1.5$ vol. \% of fiber (it was varied as $0,0.5,1$ and $1.5 \%$ of total weight of constituent material), $10 \mathrm{vol}$. \% of latex paint, $40 \mathrm{vol}$. \% of fine aggregate, $20 \mathrm{vol}$. \% of Portland cement and $28.5 \mathrm{vol}$. \% of water. The absolute volume equation was used to determine the weight of each constituent and the densities of the materials used were taken into consideration. Manual mixing was done to achieve homogenous distribution of the fibers in the composite as shown in Figure 1. To begin with, all the dry materials were weighed and kept in separate containers. Bamboo fibers were weighed and placed in labelled containers; acrylic latex paint of the determined weight of the cement was also measured.
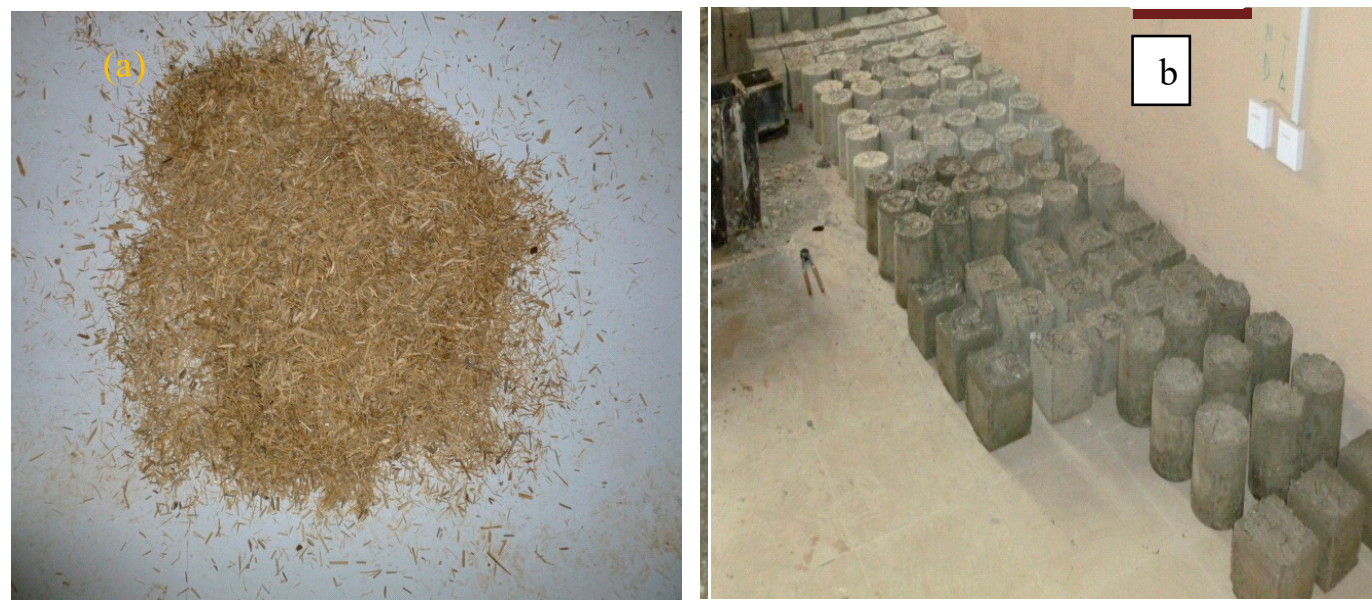

Figure 1. (a) Treated bamboo fibers from construction waste, (b) latex modified mortar samples.

The fine sand and cement were spread on the floor and mixed thoroughly; thereafter, the bamboo fibers were spread and mixed together with the rest. The fine sand to cement ratio adopted was $2: 1$, while the water to binder ratio was maintained at 0.56 . After this, half of the water was added to the measured acrylic latex paint solution and diluted thoroughly before it was poured into the already mixed constituents. The remaining half of the water was used to rinse the remaining latex solution from its container and poured into the mixture. A total of 135 samples were produced and labelled. Three samples were tested from each mix design after 28,45 and 60 days of curing. CT is the control with no fiber and polymer, $\mathrm{C}$ has $10 \%$ latex paint with no fiber, D with $0.5 \%$ fiber and $10 \%$ latex solution, A with $1 \%$ fiber and $10 \%$ latex solution and $\mathrm{R}$ with $1.5 \%$ fiber inclusion and $10 \%$ latex solution. It has been established from previous studies $[23,24]$ that the optimum latex paint constituent for the composite is $10 \%$ of cement content used.

\subsection{Testing Procedure}

\subsubsection{Mechanical Properties}

Some of the tests used in the evaluation and strength performance of natural fiber reinforced polymer mortars are compressive, flexural and tensile strength tests [25]. Therefore, $150 \mathrm{~mm}$ cubes were cast for compressive strength, cylinder sizes of $150 \times 350 \mathrm{~mm}$ for splitting tensile strength and beams of sizes $100 \times 100 \times 400 \mathrm{~mm}$ for flexural strength. 28, 45 and 60 days of air curing were carried out for all the specimens for the three tests conducted at laboratory temperature of $25^{\circ} \mathrm{C}$. 
The compressive strength test was performed in accordance with the BS 1881 standard. using a universal crushing machine with a $2000 \mathrm{kN}$ capacity, the splitting tests were conducted in accordance with ASTM [26] and a loading rate of $1.2 \mathrm{MPa} / \mathrm{min}$ was applied without shock until failure occurred, as seen in Figure 2. The flexural strength tests were conducted according to BS [27] using beams with a center point loading arrangement and loading was applied without shock.

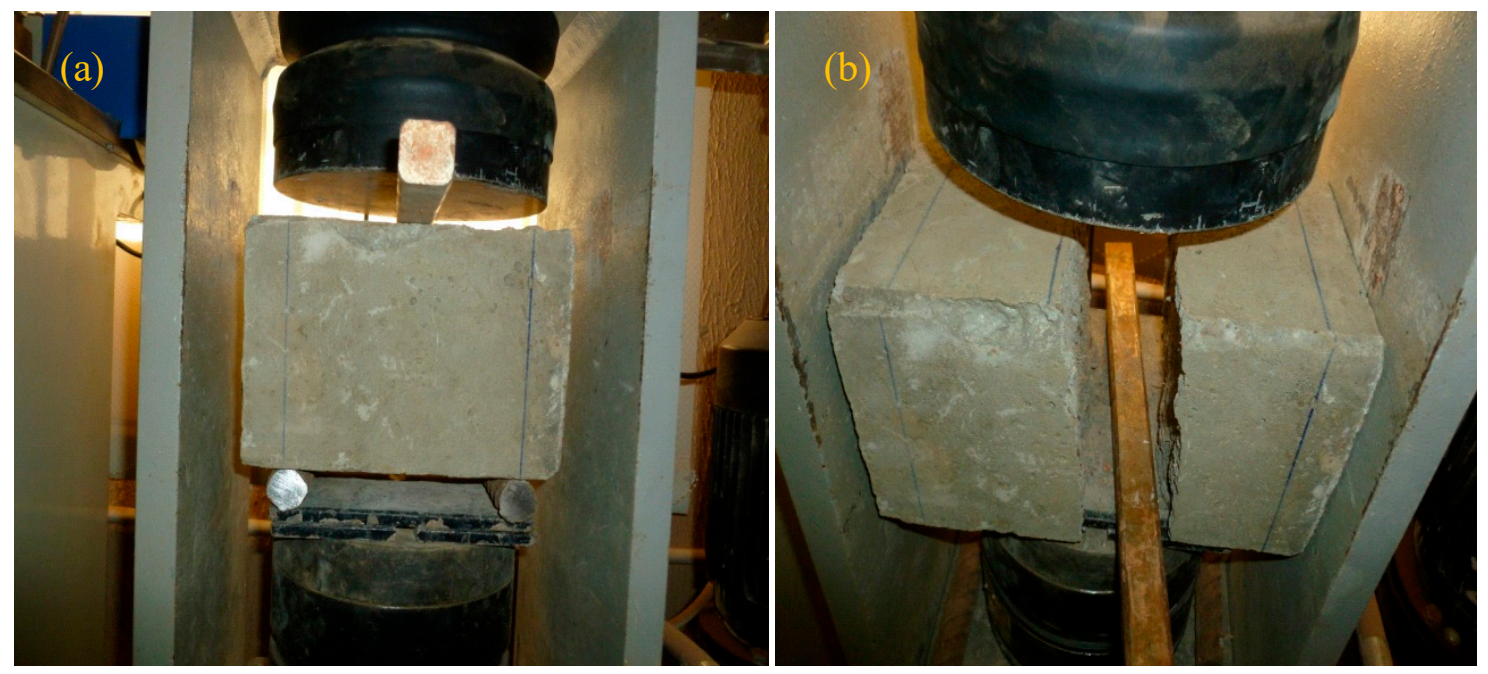

Figure 2. (a) Beam testing; (b) failure of beam.

\subsubsection{Microstructural Analysis}

The microstructural analysis was done using the Phenom ProX desktop scanning electron microscope (SEM) model MVE0224651193 (supplied by Thermo Fisher Scientific, Eindhoven, The Netherlands), which is operated at $15 \mathrm{KeV}$ using X-ray analysis to evaluate the sample structures physically. The latex polymer modified bamboo reinforced samples were carefully mounted on aluminum stubs with the aid of a conductive adhesive. The stubs were then placed on the coater stage. The samples were coated with gold using a Quorum sputter coater (model number: Q150R ES). After coating, the samples were ready for analysis, placing each sample in a standard sample holder and analyzed one after the other.

\section{Results and Discussions}

\subsection{Mechanical Properties}

\subsubsection{Compressive Strength Analysis}

The 28-day compressive strength result in Figure 3 indicated that sample $\mathrm{R}$ had the highest strength of $89.4 \mathrm{MPa}$, closely followed by sample A at $80.1 \mathrm{MPa}$. In comparing these values with the control, an improvement of $206 \%$ and $176 \%$ was observed, respectively. Sample C had a strength of $74.8 \mathrm{MPa}$, which is an increase of $157.9 \%$ in comparison with the control sample. These samples showed that they are more resistant to compressive forces with the inclusion of both latex paints and fibers, rather than when the latex paints only were added. There was a more pronounced increase in the compressive strength after 45 days because the voids and water molecules had been eliminated, though not completely since the previous test at 28 days of curing. The latex paint additive also increased the strength of the cement binder by slowing the rapid rate of hydration to a level where film formation and the evaporation of water molecules could take place simultaneously. At 28 days, the strength of sample $\mathrm{C}$ was $74.8 \mathrm{MPa}$, while at 45 days it was $82.4 \mathrm{MPa}$, which gave an increment in strength of $10.1 \%$. Additionally, at 60 days the recorded compressive strength was $86.6 \mathrm{MPa}$ which led to a $5.1 \%$ improvement in comparison with the 45 th day result. This enhanced strength is due to 
the membrane of polymer which is a constituent of the latex paint covering the cement molecules, thereby reducing the absorption of water in the unhydrated cement particles. Sample $\mathrm{R}$ values were 89.4 MPa, 97.1 MPa and 105.8 MPa for 28, 45 and 60 days, respectively. This improved early strength development of the composite is due to particle-size distributions of microfillers of the added latex paints and the amount of the fine particles in the composite material notably influenced the strength as well $[28,29]$. Fiber inclusions into the composites gave a clear improvement in the compressive strength by enhancing the resistance to compressive load. Generally, as the fibers were increased from $0.5 \%$ to $1.5 \%$, a progressive increase in compressive strength was also noted for the samples tested across the curing days. Sample D ranged from 77.3-95.7 MPa, sample A ranged from 80-101.9 MPa while sample $\mathrm{R}$ varied from 89.4-105.7 MPa. The highest value was found in sample $\mathrm{R}$, which had $1.5 \%$ fiber and $10 \%$ latex paint and produced an increment of $22 \%$ over latex paint only modified sample C. A more pronounced effect on the strength was observed in the difference between the control (conventional mortar) and sample $\mathrm{R}$ at $79.1 \%$. This is due to the combined composite actions of latex paints and natural fiber included in sample R. Bamboo has a distinctive sclerenchyma fiber internal network with small lumen and thick secondary walls, and this gives it remarkable tensile properties with which it is able to resist the formation of cracks [30]. In the same vein, crack propagation is reduced majorly by the bamboo fibers by arresting the cracks, in this way the compressive strength will improve. It is also noted that surface pre-treatment of the fibers created better bonding between the bamboo and the modified mortar through the interlocking phenomenon. This further provides a sewing effect which improves the energy absorption needed to resist crack formation and propagation [31].

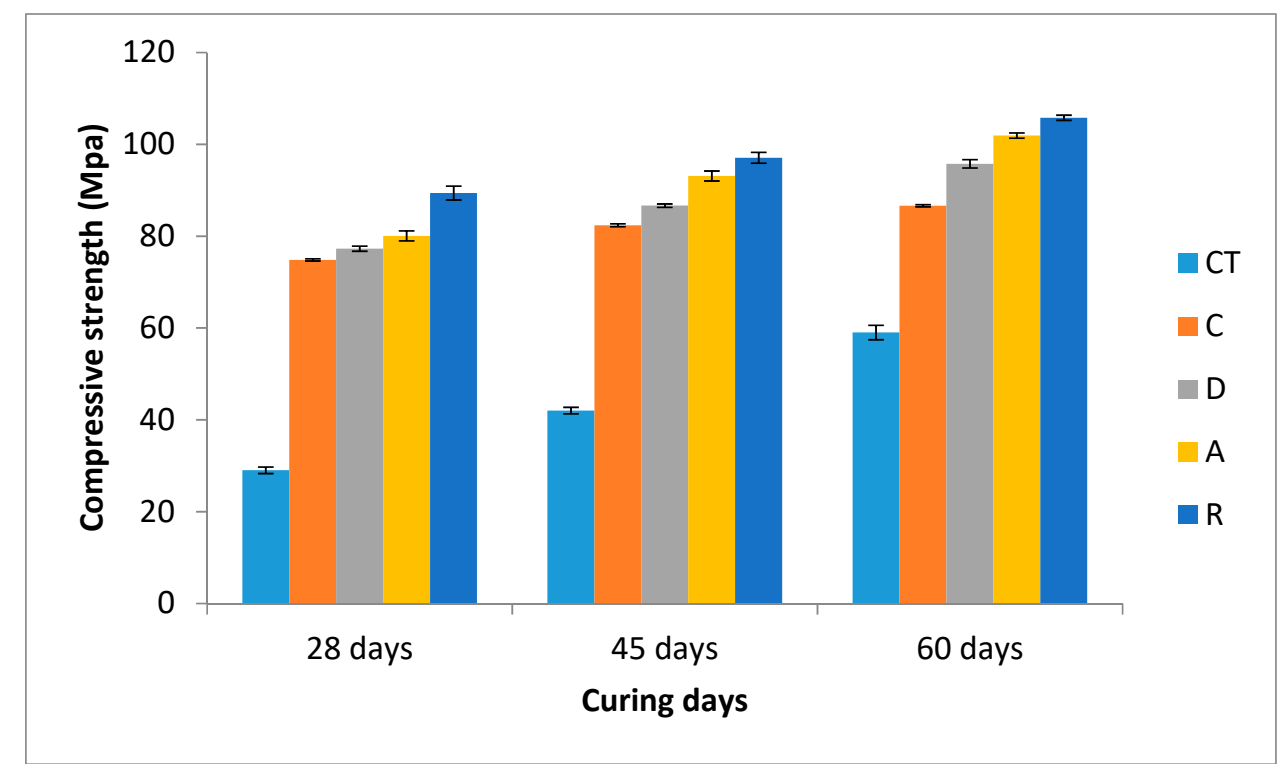

Figure 3. Compressive strength result (Legend: $\mathrm{CT}=$ control, $\mathrm{C}=10 \%$ latex, $\mathrm{D}=0.5 \%$ fiber and $10 \%$ latex, $\mathrm{A}=1 \%$ fiber and $10 \%$ latex and $\mathrm{R}=1.5 \%$ fiber and $10 \%$ latex.)

\subsubsection{Split Tensile Strength Analysis}

The split tensile results as seen in Figure 4 illustrate that the more fibers that are added, the greater the resistance to splitting of the mortars. As reported by Savastano et al. [32] natural fiber tends to give extra strength to mortars when used as reinforcement when cracks are induced due to pressure on them. At the 28th, 45th and 60th days, the values obtained ranged from $11.2-25.6 \mathrm{MPa}$ for $\mathrm{D}$ at $0.5 \%$ fiber, 18.7-36.4 MPa for A at 1\% fiber and $\mathrm{R}$ ranged from 24.8-47.7 MPa with 1.5\% fibers added; all at $10 \%$ latex paint inclusion. While sample $C$ with latex paint only ranged from 10.4-23.8 MPa and the control sample ranged from 5-18 MPa across the same curing duration. Generally, the effects of fiber reinforcement across these composite samples was more pronounced at the 45th and 60th days. This is because the fibers offered a more cohesive and combined resistance to splitting forces, more 
than the highest values obtained for the control samples. In addition, the observed improved strength when the fibers were added was because of high aspect ratio of the fibers, which led to an increase in the lateral surface area of fibers in contact with the cement and the latex paints, hence bonding between the cement, paints and the fibers increased. In addition, the high tensile strength of the fiber causes a change in the mechanism of rupture from breaking fibers to pulling out the fibers from the matrix. This means that the bonding strength between the cement, paints and the fibers controls the mechanism [33]. The increase in tensile strength of the samples was also enhanced by the rougher fiber surface morphology of the bamboo, which is as a result of the alkali treatment which removed the impurities and reduced the lignin and cellulose content. This rougher surface led to an improvement in the fiber-matrix adhesion and hence the increase in the tensile strength. Bamboo fiber degradation in the cement medium which could have reduced the strength has been reduced drastically through the surface pre-treatment; hence the bamboo fibers could perform their best in the reduction of cracks in the mortar samples.

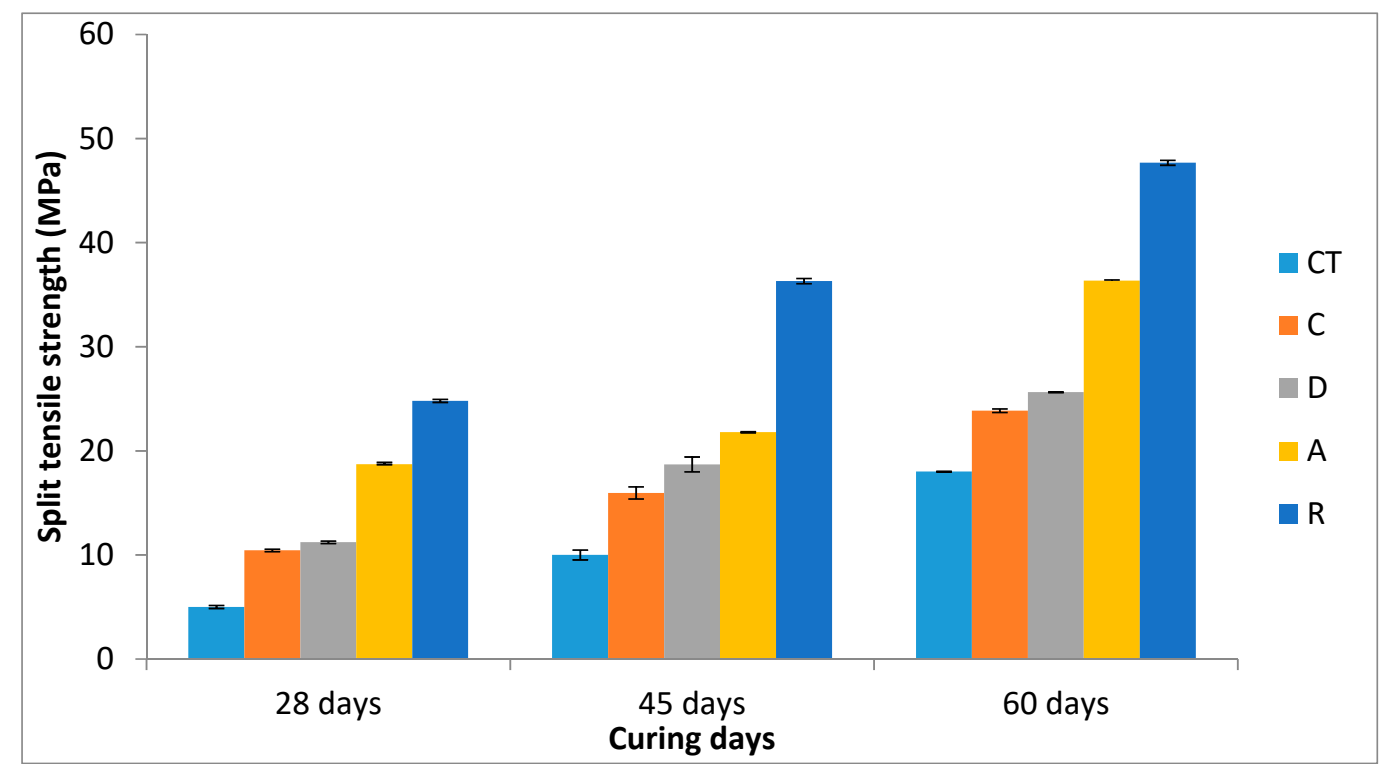

Figure 4. Split tensile strength result. (Legend: $\mathrm{CT}=$ control, $\mathrm{C}=10 \%$ latex, $\mathrm{D}=0.5 \%$ fiber and $10 \%$ latex, $\mathrm{A}=1 \%$ fiber and $10 \%$ latex and $\mathrm{R}=1.5 \%$ fiber and $10 \%$ latex.)

\subsubsection{Flexural Strength Analysis}

The curing duration had a positive effect on the majority of the tested samples by improving the formation of polymer films and enhancing the ductility and toughness of the bamboo fibers for samples with fiber reinforcement, which led to a higher resistance to cracks due to the transferred stress from the mortar to the fibers [34] as seen in Figure 5. 45 days curing of sample $C$ had $100 \%$ higher flexural strength than the 28th day, likewise the 60th day strength was $80 \%$ higher than 45th day. This pattern was also observed in sample $\mathrm{R}$, with more strength recorded as the curing days progressed. At the 28th, 45th and 60 th days the values were $26.3 \mathrm{MPa}, 30.7 \mathrm{MPa}$ and $51.7 \mathrm{MPa}$, respectively. The control sample clearly showed lower flexural strength in comparison with the least flexural strength observed at sample D among the fiber reinforced samples. Sample D values ranged from 16.2-39.2 MPa at 28th, 45th and 60th days, as against 7-23 MPa for the control at the respective curing days. For composite samples with fiber reinforcement, most of them had a flexural strength improvement as the curing days increased. Sample R had 16.7\% higher strength on the 45th day, more than the 28th day, while the 60th day had a flexural strength of $68.4 \%$ higher than the 45 th day. In a recent study [35] on the effect of variable curing time on the mechanical strength of mortar, it was stated that mortar is a curing time dependent material and the behavior of the plastic deformation and failure strength is highly dependent on curing time. With the increase of curing time, the effect on 
deformation and failure strength could either increase or decrease. A trend of increase and decrease in strength was also reported [36] when a variable curing regime of 7, 14, 28 and 90 days was adopted to study the effects on some mechanical properties of pre-soaked recycled mortar. There was a general steady and substantial increase in flexural strength across the mixes of the composites tested, which is caused by the bonding of the interfacial transition zone that exists around the cement matrix and the aggregates, as well as the closing up of micro-cracks by the latex polymers as they are initiated under stress [37]. The inclusion of bamboo fibers also played a major role by inhibiting the propagation of these cracks. The ductility property added on the inclusion of bamboo fibers when compared with the control samples led to an improved flexural strength of the samples. The fibers were added to improve the strength, control the cracking of the fiber reinforced mortar, and to alter the behavior of the material once the matrix has cracked by bridging across these cracks and so providing some post-cracking ductility [38]. The improved bonding between the bamboo fiber and the matrix may be credited to cement precipitation into the fibril exposed surface and the fiber cavities. Thereafter, the interfacial bond was developed between the cellulose chain of bamboo fibers and calcium based hydrated product of the cement. This greatly improved the crack resistance and reduced the crack propagation mechanism of the composite samples.

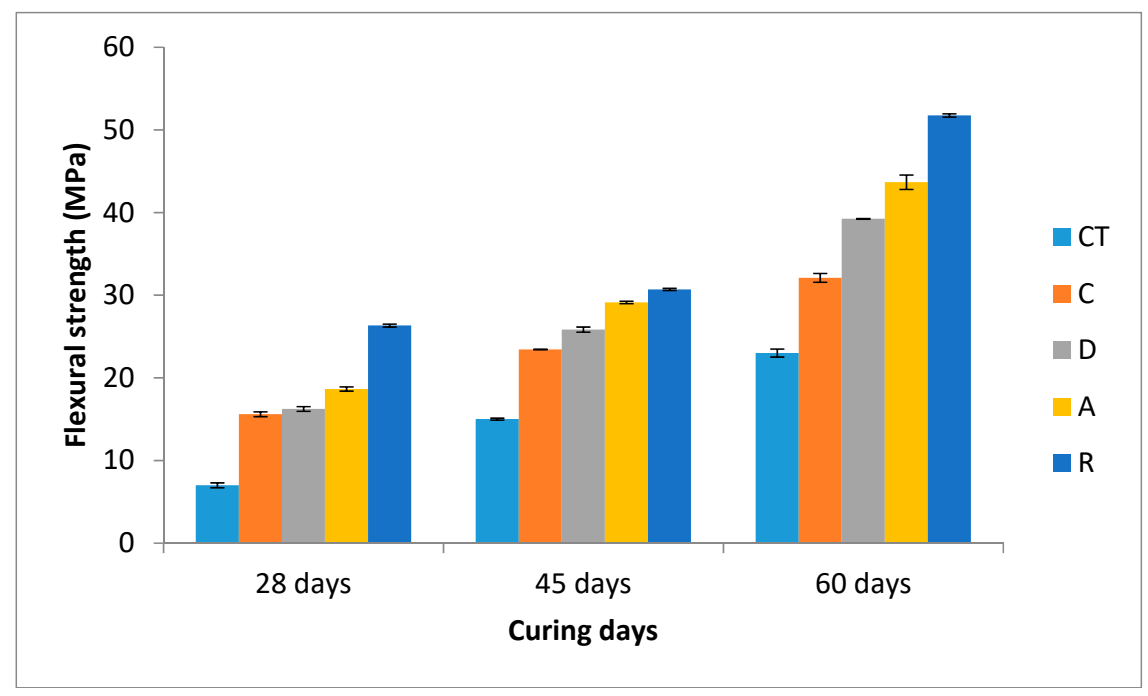

Figure 5. Flexural strength result. Legend: $\mathrm{CT}=$ control, $\mathrm{C}=10 \%$ latex, $\mathrm{D}=0.5 \%$ fiber and $10 \%$ latex, $\mathrm{A}=1 \%$ fiber and $10 \%$ latex and $\mathrm{R}=1.5 \%$ fiber and $10 \%$ latex.

\subsection{Microstructural Analysis Result}

The scanning electron microscope (SEM) obtained for the bamboo reinforced acrylic polymer cement composite in Figures 6 and 7 showed agglomerated acrylic emulsion latex precipitated in the hollows and on the surface of the bamboo fibers. The micrograph showed gels of calcium silicate hydrates $(\mathrm{C}-\mathrm{S}-\mathrm{H})$, and unhydrated Portland cement clinker grain. Due to their size and very low interconnectivity, these pores are relatively impermeable to water, which is in agreement with the physical properties conducted on the samples. Capillary voids (voids created by water particle movements and space not occupied by solid components) are also seen in the image obtained in Figure 6, these also are major contributors to the porosity of the composite mortar. The size of capillary voids is much larger at the interfacial zone, which is the region at the interface of the aggregate and the hydrated cement paste compared to the bulk cement paste. When the fiber and the matrix combine, organic composition and hydration products in the matrix diffuse each other. These cause the solid and dense materials formed in this layer, and lead to improved mechanical properties when compared with the control samples without neither fiber nor polymer inclusion, as seen in Figure 6. It was clearly observed that the formation of polymer clusters or latex films deposited in the interface 
layer between the fibers and cement matrix, and the hydrated products of cement also appear in this layer. The presence of these materials together leads to a formation of a network structure as a result of the reaction between the hydrated products and the polymeric materials, as shown in Figure 7. The interconnectivity between these materials is accompanied by an improvement in the mechanical properties of these composites which is more than that of the control samples. These qualities coupled with enhanced bond strength give birth to a composite material of higher strength and lower ductility [39]. When the fibers and matrix are combined, acrylic polymer emulsion forms the interface and the hydration products of the matrix diffuse reciprocally, therefore the density of this area is relatively high.

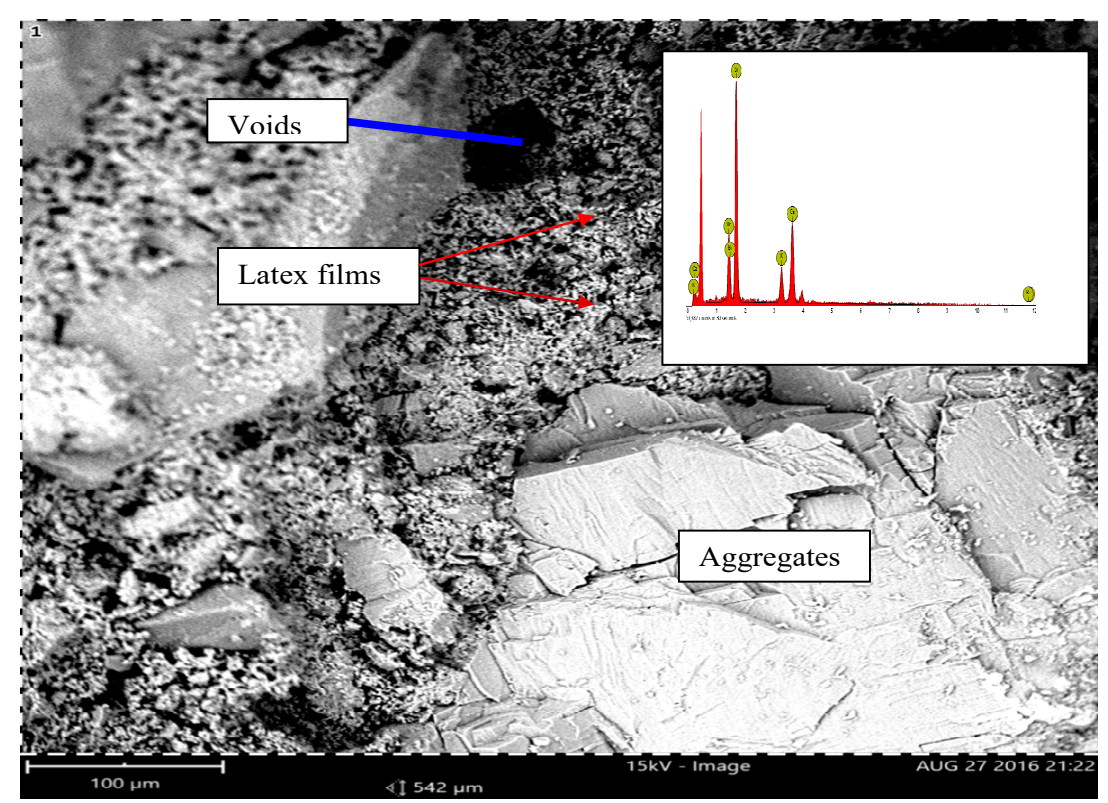

Figure 6. SEM analysis and EDS spectra of sample C.

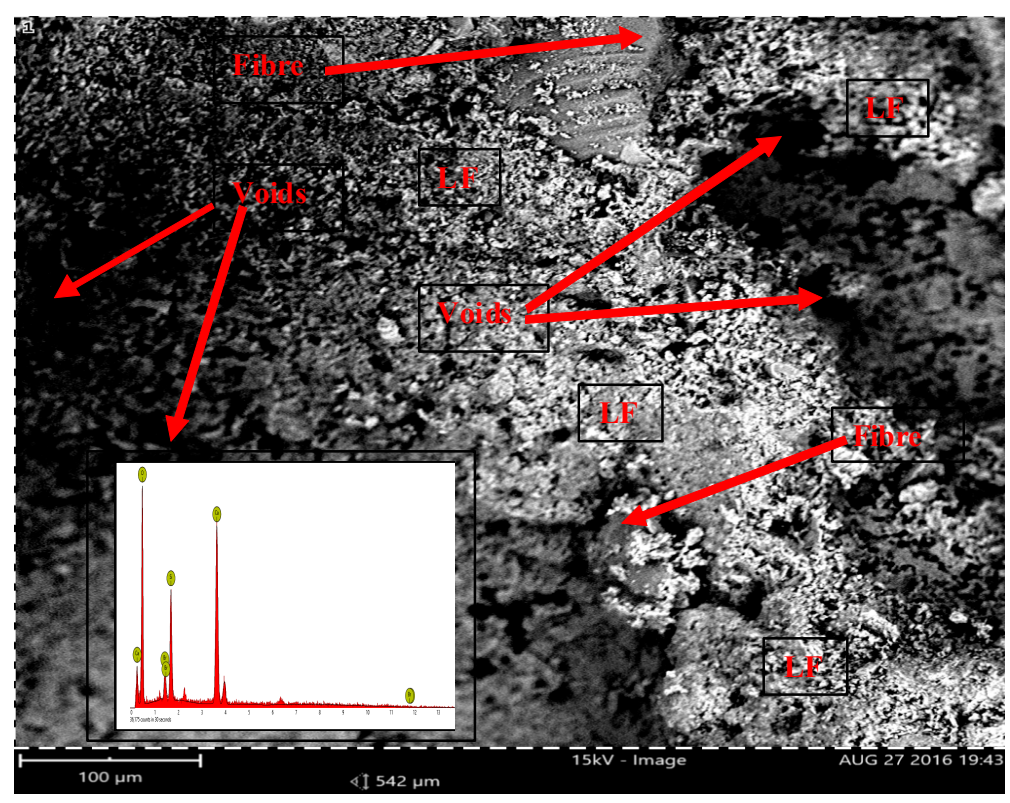

Figure 7. SEM analysis and EDS spectra of sample D (LF-latex films).

Energy dispersive spectroscopy (EDS) elemental characterization for sample C indicated a $42.1 \%$ concentration of silicon which could exist in the sample in oxide form. Calcium accounts for $28.1 \%$, aluminum at $18.6 \%$ and potassium at $11.2 \%$. Elemental compositions of sample D are silicon at $38.7 \%$, 
calcium at $50.6 \%$ and aluminum at $10.7 \%$. All these elements are major oxides found after cement hydration could have taken place. These also confirm the presence of some of the elements identified in the SEM micrograph which are C-S-H gels.

\section{Conclusions}

The following conditions could be arrived at from the study:

1. Bamboo reinforcement at $1.5 \%$ and latex paint addition of $10 \mathrm{wt}$. $\%$ of cement gave the optimal value which produced excellent performance in compressive, split tensile and flexural strength tests during the adopted curing duration.

2. The improved strength noted was due to the improved interfacial bond in the fiber-matrix, surface pre-treatment with $\mathrm{NaOH}$, and the micro-fillers supplied by the latex paints which together contributed to better crack reduction tendencies in the samples.

Author Contributions: B.A. sourced for the materials, conducted the research and the write up was also done by him. T.O. provided supervision for the study.

Funding: This research received no external funding

Acknowledgments: The technical support provided by personnel in Civil Engineering is appreciated. The authors also appreciate Landmark University research fund for providing the APC.

Conflicts of Interest: The Authors declare no conflicts of interest.

\section{References}

1. Ahmed, M.D.; Hafez, E.E.; Ali, H.A. Experimental investigation of the effect of latex solid/water ratio on latex modified co-matrix mechanical properties. Alex. Eng. J. 2013, 52, 83-98.

2. Hyug-Moon, K.; Thuy, N.N.; Tuan, A.L. Improvement of the Strength of Acrylic Emulsion Polymer-modified Mortar in High Temperature and High Humidity by Blast Furnace Slag. KSCE J. Civ. Eng. 2009, 13, $23-30$. [CrossRef]

3. Mehta, P.K. Mortar, Microstructure, Properties, and Materials; McGraw-Hill: New York, NY, USA; Chicago, IL, USA; San Francisco, CA, USA; Lisbon, Portugal; London, UK; Madrid, Spain, 2006.

4. Ohama, Y. Handbook of Polymer Modified Mortar and Mortars; Noyes Publications: Ann Arbor, MI, USA, 1995.

5. Dionys, A.V.G.; Elke, K. Contribution of C-PC to sustainable construction procedures. In Proceedings of the 13th International Congress in Polymers in Mortar, Madeira, Portugal, 10-12 February 2010.

6. Hassan, K.E.; Robery, P.C.; Al-Alawi, L. Effect of hot-dry curing environment on the intrinsic properties of repair materials. Cem. Mortar Compos. 2002, 22, 453-458. [CrossRef]

7. Jenni, A.; Zurbriggen, R.; Holzer, L.; Herwegh, M. Changes in microstructure and physical properties of polymer modified mortars during wet storage. Cem. Mortar Res. 2002, 36, 79-90. [CrossRef]

8. Scott Hamel, P.E.; Nathaniel Cox, E.I.T. Design and Evaluation of Thin-Shell Latex-Modified Mortar Barrel Roof Units; Research Publication of University of Alaska Anchorage: Anchorage, AK, USA, 2013.

9. Haigh, C.J. Latex and Acrylic Based Waste Paint as Admixture in Mortar Masonry Blockfill. Master's Thesis, University of Auckland, Auckland, New Zealand, 2007.

10. Lagerblad, B.; Vogt, C. Ultrafine Particles to Save Cement and Improve Mortar Properties; Draft Report; CBI: Stockholm, Sweden, 2003.

11. Gretz, M.; Plank, J. An ESEM investigation of latex film formation in cement pore solution. Cem. Mortar Res. 2011, 41, 184-190. [CrossRef]

12. Giustozzi, F. Polymer-modified pervious mortar for durable and sustainable transportation infrastructures. Constr. Build. Mater. 2016, 111, 502-512. [CrossRef]

13. Huang, B.; Wu, H.; Shu, X.; Burdette, E.G. Laboratory evaluation of permeability and strength of polymer-modified pervious mortar. Constr. Build. Mater. 2010, 24, 818-823. [CrossRef]

14. Jamshidi, M.; Pakravan, H.R.; Zojaji, K. Correlation between water permeability of latexmodified mortar (LMC) and water diffusion coefficient of latex film. Iran. Polym. J. 2013, 22, 799-809. [CrossRef]

15. Jamshidi, M.; Pakravan, H.R.; Pourkhorshidi, A.R. Application of Polymer Admixtures to Modify Mortar Properties: Effects of Polymer Type and Content. Asian J. Civ. Eng. (BHRC) 2014, 15, 779-787. 
16. Chen, J.; Chouw, N. Compressive behaviour of flax FRP double tube confined coconut fiber reinforced mortar. Constr. Build. Mater. 2016, 112, 666-673. [CrossRef]

17. Yan, L.; Chouw, N. Dynamic and static properties of flax fiber reinforced polymer tube confined coir fiber reinforced mortar. J. Compos. Mater. 2014, 48, 1595-1610. [CrossRef]

18. Mokhtari, A.; Nejad, F.M. Mechanistic approach for fiber and polymer modified SMA mixtures. Constr. Build. Mater. 2012, 36, 381-390. [CrossRef]

19. Chakraborty, S.; Kundu, S.P.; Roy, A.; Adhikari, B.; Majumder, S.B. Polymer modified jute fibre as reinforcing agent controlling the physical and mechanical characteristics of cement mortar. Constr. Build. Mater. 2013, 49, 214-222. [CrossRef]

20. Atanda, J. Environmental impacts of bamboo as a substitute Constructional material in Nigeria. Case Stud. Constr. Mater. 2015, 3, 33-39. [CrossRef]

21. Ghavami, K. Bamboo as reinforcement in structural mortar elements. Cem. Mortar Compos. 2005, 27, 637-649. [CrossRef]

22. Yan, L.; Chouw, N.; Huang, L.; Kasal, B. Effect of alkali treatment on microstructure and mechanical properties of coir fibers, coir fiber reinforced-polymer composites and reinforced-cementitious composites. Constr. Build. Mater. 2016, 112, 168-182. [CrossRef]

23. Akinyemi, B.A.; Omoniyi, T.E. Engineering properties of acrylic emulsion polymer modified bamboo reinforced cement bonded composites. Eng. Struct. Technol. 2017, 9, 126-132. [CrossRef]

24. Akinyemi, B.A.; Omoniyi, T.E. Effect of moisture on thermal properties of acrylic polymer modified mortar reinforced with alkali treated bamboo fibers. J. Indian Acad. Wood Sci. 2018, 15, 45-51. [CrossRef]

25. ASTM C496-(2017). Standard Test Method for Splitting Tensile Strength of Cylindrical Mortar Specimens; ASTM International: West Conshohocken, PA, USA, 2017.

26. BS EN 12390-5:(2009), Testing Mortar. Method for Determination of Flexural Strength; British Standards Institution: London, UK, 2009.

27. Tian, Y.; Jin, X.; Jin, N.; Zha, R.; Li, Z.; Ma, H. Research on the microstructure formation of polyacrylate latex modified mortars. Constr. Build. Mater. 2013, 47, 1381-1394. [CrossRef]

28. Almesfer, N.; Ingham, J. Effect of waste latex paint on mortar. Cem. Mortar Compos. 2014, 46, 19-25. [CrossRef]

29. Rahman, N.; Shing, L.W.; Simon, L.; Philipp, M.; Alireza, J.; Ling, C.S.; Nee, S.S. Enhanced bamboo composite with protective coating for structural mortar application. Energy Procedia 2017, 143, 167-172. [CrossRef]

30. Farooqi, M.U.; Ali, M. Contribution of plant fibers in improving the behavior and capacity of reinforced mortar for structural applications. Constr. Build. Mater. 2018, 182, 94-107. [CrossRef]

31. Savastano, H.; Santos, S.F.; Radonjic, M.; Soboyejo, W.O. Fracture and fatigue of natural fiber-reinforced cementitious composites. Cem. Mortar Compos. 2009, 31, 232-243. [CrossRef]

32. Khorami, M.; Sobhani, J. An experimental study on the flexural performance of agro-waste cement composite boards. Int. J. Civ. Eng. 2013, 11, 207-216.

33. Claramunt, J.; Ardanuy, M.; García-Hortal, J.A.; Tolêdo Filho, R.D. The hornification of vegetable fibers to improve the durability of cement mortar composites. Cem. Mortar Compos. 2011, 33, 586-595. [CrossRef]

34. Chen, D.; Yu, X.T.; Shen, J.; Zhang, Y. Investigation of the curing time on the mechanical behaviour of normal mortar under triaxial compression. Constr. Build. Mater. 2017, 147, 488-496. [CrossRef]

35. Pickel, D.; Tighe, S.; West, J.S. Assessing benefits of pre-soaked recycled mortar aggregate on variably cured mortar. Constr. Build. Mater. 2017, 141, 245-252. [CrossRef]

36. Paschal, S.; Aliche, A.; Pilvin, P. Mechanical behaviour of polymer modified mortars. Mater. Sci. Eng. A 2004, 380, 1-8. [CrossRef]

37. Sukumar, A.; John, E. Fiber Addition and its Effect on Mortar Strength. Int. J. Innov. Res. Adv. Eng. 2014, 1, 144-149.

38. Romildo, D.T.; Toledo, F.; Karen, S.; George, L.E.; Khosrow, G. Durability of alkali-sensitive sisal and coconut fibers in cement mortar composites. Cem. Mortar Compos. 2000, 22, 127-143.

39. Ismail, M.R.; Youssef, H.A.; Magdy AM, A.; Zahran, A.H.; Afifi, M.S. Utilization of Emulsion Polymer for Preparing Bagasse Fibers Polymer-Cement Composites. J. Appl. Polym. Sci. 2008, 107, 1900-1910. [CrossRef]

(C) 2018 by the authors. Licensee MDPI, Basel, Switzerland. This article is an open access article distributed under the terms and conditions of the Creative Commons Attribution (CC BY) license (http:/ / creativecommons.org/licenses/by/4.0/). 